\title{
Knowledge about Tuberculosis in outpatients who visited College of Medical Sciences Teaching Hospital, Bharatpur, Nepal
}

\author{
Manandhar N. , Krishna G. \\ Department of Community Medicine, College of Medical Sciences, Bharatpur, Nepal \\ Correspondence Address: Naresh Manandhar, Department of Community Medicine, College of Medical Sciences, \\ Bharatpur, Nepal
}

\begin{abstract}
Background: Now a days Tuberculosis is a major public health problem in the world. Number of deaths due to tuberculosis is highest among the infectious diseases.

Methods: The cross sectional study was carried out from May 2008 to July 2008 in the different out patient departments of College of Medical Sciences Teaching Hospital. A total of 500 patients belong to age $>15$ years who visited various departments of College of Medical Sciences Teaching Hospital were randomly selected for the present study. Interview technique was used to collect information on a pre-designed and pre-tested questionnaire.

Results: Out of total patient's interview, $59 \%$ and $41 \%$ were male and female respectively. Majority of the outpatients had heard about the Tuberculosis disease. $73.3 \%$ of the respondents opinioned that T.B. can be acquired by infection.

Conclusion: The study population has satisfactory knowledge about the etiology and transmission of the disease. There was poor knowledge about proper disposal of sputum which is an important aspect in regard to transmission of disease. There is need of imparting knowledge to the people about proper disposal of sputum to reduce the spread of disease and mortality due to T.B
\end{abstract}

Key words: Knowledge, Prevention, Transmission, Tuberculosis

\section{Introduction}

Tuberculosis (T. B.) was known by various names in ancient days like Scrofula, King evil, Phthisis, Decline, Rajayakshma, Kshyaroga etc.. T. B. is an infectious disease caused by the bacillus ${ }^{1}$.

Today, Tuberculosis is a world wide public health problem; despite the fact that the causative organism was discovered more than 100 years ago, and highly effective drugs and vaccine are available, making Tuberculosis preventable and curable diseases ${ }^{1}$. Globally, there were 9.27 million new cases of T.B. occurred in 2007, of which 4.1 million were smear positive. The global incidence of T.B. is growing at $1.1 \%$ per year and number of cases at $2.4 \%$ per year. 1.32 million people died of T.B. and the global burden of disease in terms of DALYS lost was about 34.73 million $^{2}$. Most of the new cases and deaths occurred in developing countries. SEAR countries carry $38 \%$ of global burden of T.B. with 3 million new cases and 0.6 million deaths occurring every year 3.8 out of 10 who suffered by T.B. are in economical productive age group. T. B. kills more than any other infectious diseases. T. B. is one of major public health problem in Nepal. About $45 \%$ of total population is infected with T.B., out of which $60 \%$ are in the productive age group. Every year 40,000 people develop active T.B. among them 20,000 people have infectious pulmonary disease. These 20,000 people are able to transmit the disease to others ${ }^{4}$. By 2002, 180 countries have implemented Address for correspondence: Naresh Manandhar, Assistant Professor, Department of Community Medicine, College of Medical Sciences, Bharatpur, Chitwan, Nepal. Email: nareshsayami@yahoo.com

DOTS strategy covers $69 \%$ of world population. In Nepal, DOTS Strategy has been implemented since 1996 and has already reduced the number of deaths. By 2008, DOTS has been expanded to 1079 treatment centers with 3147 sub- 
centers in Nepal, with $94 \%$ of population covered4. However 5000-7000 people still die per year from T.B. in Nepal. Expansion of this cost effective and highly successful treatment strategy has proven its efficacy on reducing the mortality and morbidity in Nepal.

\section{Methods}

The cross sectional study was carried out from May 2008 to July 2008 in the different out patient departments of College of Medical Sciences Teaching Hospital. A total of 500 patients belong to age $>15$ years who visited various departments of College of Medical Sciences Teaching Hospital were randomly selected for the present study. Interview technique was used to collect information on a pre-designed and pre-tested questionnaire. The collected data were entered in computer using SPSS software. The data were presented in different tables and statistical analysis was done wherever it was required.

\section{Results}

Table 1: Age and sex wise distribution of the respondents

\begin{tabular}{|c|c|c|c|c|c|c|}
\hline \multirow{2}{*}{$\begin{array}{l}\text { Age group } \\
\text { (in years) }\end{array}$} & \multicolumn{4}{|c|}{ Sex } & \multirow{2}{*}{ Total } & \multirow{2}{*}{ Percentage } \\
\hline & Male & Percentage & Female & Percentage & & \\
\hline $15-19$ & 12 & 4.1 & 6 & 2.9 & 18 & 3.6 \\
\hline $20-24$ & 23 & 7.8 & 12 & 5.9 & 35 & 7.0 \\
\hline $25-29$ & 86 & 29.2 & 51 & 24.9 & 137 & 27.4 \\
\hline $30-34$ & 75 & 25.4 & 54 & 26.3 & 129 & 25.8 \\
\hline $35-39$ & 32 & 10.8 & 28 & 13.7 & 28 & 5.6 \\
\hline $40+$ & 67 & 22.7 & 54 & 26.3 & 54 & 10.8 \\
\hline Total & 295 & 100.0 & 205 & 100.0 & 500 & 100.0 \\
\hline
\end{tabular}

$\mathrm{P}$ value $<0.0001$

In this study, 295 were male ( $59 \%$ ) and 205 were female (41\%).In the age wise distribution, the maximum patients $(27.4 \%)$ were from age group $25-29$ years followed by $(25.8 \%)$ from age group 30-34 years. The least number of patients $(3.6 \%)$ were from age group 15-19 years. There is a significant difference in age and sex wise distribution of patients since the $\mathrm{p}$ value is less than 0.05 .. (Table 1 )

Out of 500 total study population, $98.8 \%$ of the outpatients had heard about the Tuberculosis. The Majority of patients (73.3\%) said infection was the aetiology of disease followed by smoking (17.8\%) and alcohol (14.4\%). The few percentage of the patient said curse, sin and hereditary was the aetiology of disease.

The disease will spread with close contact with a T.B. patient. This opinion was given by $51.0 \%$ of total patients where as $36 \%$ of the patient opinioned that the disease will spread through coughing. The few percentage of the patient opinioned that the disease will spread through sharing utensil \& cloths $(2.6 \%)$, unsterilized syringe \& needles $(0.8 \%)$ and receiving \& donating blood $(0.6 \%)$.

$44.8 \%$ of the respondents viewed that other family member were at risk to develop the disease if any family member was suffering from the T.B. $35.0 \%$ of the respondents viewed that smokers were at risk to develop the disease followed by overcrowding $(5.6 \%)$, breast feed infants $(4.2 \%)$ and children with mother having T.B. (3.6\% ). 
Table 2: Knowledge about Aetiology, Spread, at risk person, Signs \& symptoms and Prevention of Tuberculosis. (Multiple response)

\begin{tabular}{|c|c|c|}
\hline Aetiology & Number & Percentage \\
\hline Curse & 12 & 2.4 \\
\hline Sin & 28 & 5.6 \\
\hline Infection & 369 & 73.8 \\
\hline Alcohol & 72 & 14.4 \\
\hline Smoking & 89 & 17.8 \\
\hline Hereditary & 12 & 2.4 \\
\hline Spread & Number & Percentage \\
\hline $\begin{array}{l}\text { Close contact with a T.B. } \\
\text { patient }\end{array}$ & 255 & 51.0 \\
\hline Coughing & 170 & 36.0 \\
\hline $\begin{array}{l}\text { Sharing utensil and } \\
\text { cloths }\end{array}$ & 13 & 2.6 \\
\hline $\begin{array}{l}\text { Unsterilised syringe and } \\
\text { needles }\end{array}$ & 4 & 0.8 \\
\hline $\begin{array}{l}\text { Receiving and donating } \\
\text { blood }\end{array}$ & 3 & 0.6 \\
\hline At risk person & Number & Percentage \\
\hline Smoker & 175 & 35.0 \\
\hline Family member & 224 & 44.8 \\
\hline Breast feed infants & 22 & 4.2 \\
\hline $\begin{array}{l}\text { Children with mother } \\
\text { having T.B. }\end{array}$ & 18 & 3.6 \\
\hline Overcrowding & 28 & 5.6 \\
\hline Signs and symptoms & Number & Percentage \\
\hline Cough & 403 & 80.6 \\
\hline Chest pain & 262 & 52.4 \\
\hline Fever & 182 & 36.4 \\
\hline Blood in sputum & 64 & 15.8 \\
\hline Weight loss & 58 & 11.2 \\
\hline Night sweat & 10 & 2.0 \\
\hline Prevention & Number & Percentage \\
\hline $\begin{array}{l}\text { Covering the mouth at } \\
\text { the time of coughing }\end{array}$ & 272 & 54.4 \\
\hline $\begin{array}{l}\text { Proper disposal of } \\
\text { sputum }\end{array}$ & 33 & 6.6 \\
\hline Avoiding overcrowding & 58 & 11.6 \\
\hline Avoiding smoking & 96 & 19.2 \\
\hline Vaccination & 40 & 8.2 \\
\hline
\end{tabular}

$80.6 \%$ of the respondents answered that the cough was the chief complaint of T.B. followed by chest pain (52.4\%), fever $(36.4 \%)$,blood in sputum and weight loss(15.8\%). Only $2 \%$ of the respondents answered that the night sweat was the chief complaint of T.B.

$54.4 \%$ of the respondents had knowledge of prevention of T.B. by covering the mouth at the time of coughing. $19.2 \%$ and $11.6 \%$ of the respondents replied that T.B. can be prevented by avoiding smoking and overcrowding respectively. The knowledge of proper disposal of sputum was present only in $6.6 \%$ of the respondents and $8.2 \%$ of the respondents had knowledge of prevention of T.B. by vaccination. (Table 2)

\section{Discussion}

Tuberculosis is a curable disease that kills millions of people in the developing world ${ }^{5}$. Tuberculosis is a common public health problem in developing countries. Majority of problem is exposed to various media, publicity and other modes of imparting awareness regarding various diseases. Still death due to tuberculosis is highest among infectious disease. For containment of occurrence \& progression one must have basic Knowledge about disease. With this aim the present study carried out among patients attending outdoor of CMSTH, Bharatpur. The present study population comprise of $59 \%$ male and $41 \%$ female. This result is consistent with study done in Punjab, India Where $56.42 \%$ were male and $43.58 \%$ were female 6 . In our study, $98.8 \%$ of the respondents had heard about the Tuberculosis. This finding was found to be higher than the finding of UP Singh4 (81.4\%) This difference may be due to increasing role of media. $73.3 \%$ of the study population was of opinion that Tuberculosis is the result of some infection followed by the smoking (17.8\%) and alcohol (14.4\%).

Around $80 \%$ of total patients opined that the disease could spread with close contact with a T.B. patient and through coughing. This result was similar to the finding of studies by Tanimowo M.O.7 and P.E. Mogesho8 where it was $70.9 \%$ and approximately $80 \%$ respectively.

Regarding the question who will be at risk, $44.8 \%$ of the respondents viewed that other family member of T. B. patient was at risk to develop the disease. $35.0 \%$ of the respondents viewed that smokers were at risk to develop the disease followed by overcrowding (5.6\%), breast feed infants $(4.2 \%)$ and children with mother having T.B.(3.6\%).

In the present study, $80.6 \%$ of the patients responded that the cough was the chief complaint of T.B. which is quite high when compare with the study conducted by Tanimowo M.O7. where it was only $43.6 \%$. The fever was sign and symptoms of T.B. patient responded by $36.4 \%$ which 
was not conformant with the finding of Tanimowo M.O.7 $(64.6 \%)$. These variations may be due to different sample population.

Regarding the prevention of Tuberculosis, it was found that $54.4 \%$ of the respondents said by covering the mouth at the time of coughing, T.B could be prevented followed by avoiding smoking (19.2\%) and overcrowding (11.6\%). This result was not consistent with the finding of Tanimowo M.O7. (89.2\%). The knowledge of proper disposal of sputum was present only in $6.6 \%$ of the respondents and $8.2 \%$ of the respondents had knowledge of prevention of T.B. by vaccination.

\section{Conclusion}

The study population has satisfactory knowledge about the etiology and transmission of the disease. There was poor knowledge about proper disposal of sputum which is an important aspect of T.B. control. Tuberculosis is a common public health problem in developing countries. There is need of imparting knowledge to the people about proper disposal of sputum to reduce the spread of disease and death due to Tuberculosis. It is important for TB control program to have reliable laboratory facilities for susceptibility testing of M. Tuberculosis isolates

\section{Acknowledgement}

The authors would like to thank the Principal, Dr. A.C. Patowary for continuous guidance and giving permission to conduct the survey in the hospital. We would also like to thank the interns posted in the department of Community Medicine who helped in collection of data.

\section{References:}

1 The text book of Preventive and Social Medicine, K. Park, 19th edition, 2007, M/S Banarsidas Bhanot, Prem Nagar, Jabalpur, India:137-141.

2. World Health Organization, Global Tuberculosis control, Epidemiology Strategy Financing, WHO, 2009.

3. Antibiotic susceptibility pattern of mycobacterium tuberculosis, Subba S. et al, Journal of Nepal Health Research Council, Ramshah Path, Kathmandu, Nepal, Vol. 7, No.1, Issue 14, April 2009; 33-41.

4. Annual Report, 2007/2008, Department of Health Service, Govt. of Nepal, Ministry of Health and Population, Department of Health Service, Teku, Kathmandu, Nepal, 2009:155-160..

5. STC Newsletter, SAARC TB and HIV/ AIDS Centre, Thimi, Bhaktapur, Nepal, Vol. XVII, No.1, Jan- June
2007:14.

6. Knowledge about tuberculosis in senior school students of Punjab, U P Singh et al, Indian Journal of Community Medicine, PGIMRE, Chandigarh, India, Vol. 31, No. 2, April - June 2006, 93-95.

7. Knowledge, attitude and practices regarding tuberculosis among senior secondary students: Tanomowo, M.O.,East African Medical Journal,1999 Jan.,76(1): 47-50

8. Community knowledge, attitude and practices towards tuberculosis and its treatment in Mpwapwa district, Central Tanzania: P.E. Mongesho et al, Tanzania Health Research Bulletin, Vol. 9,No.1, 2007:38-43.. 